\title{
As Forças-Tarefas do Ministério Público Federal: \\ o discurso político punitivo anticorrupção na instituição de garantias
}

\author{
The Task Forces of the Federal \\ Prosecutor Service: the anti-corruption political \\ discourse in the institution of guarantees
}

\section{Antonio Eduardo Ramires Santoro ${ }^{1}$}

Universidade Federal do Rio de Janeiro - Rio de Janeiro/RJ, Brasil Universidade Católica de Petrópolis, Petrópolis/RJ, Brasil antoniosantoro@antoniosantoro.com.br

(9 http://lattes.cnpq.br/9190879263950156

Dib http://orcid.org/0000-0003-4485-844X

Carolina Cyrillo ${ }^{2}$

Universidade Federal do Rio de Janeiro - Rio de Janeiro/RJ, Brasil

Universidade de Buenos Aires - Buenos Aires, Argentina carolinacyrillo@direito.ufrj.br

http://lattes.cnpq.br/0095771869278241

http://orcid.org/0000-0003-2783-8025

1 Pós Doutor em Democracia e Direitos Humanos pela Universidade de Coimbra Portugal. Pós-Doutor em Direito Penal e Garantias Fundamentais pela Universidade de La Mantanza - Argentina; Doutor e Mestre em Filosofia pela UFRJ. Metre em Direito pela Universidade de Granada - Espanha. Professor Titular de Direito Processual Penal do IBMEC. Professor Adjunto do PPGD da UFRJ. Professor Adjunto do PPGD da UCP. Advogado Criminalista.

2 Doutoranda em Teorias Contemporâneas do Direito pelo PPGD/ UFRJ e em Direito Constitucional pela UBA. Mestre em Direito pela UFSC. Professora de Direito Constitucional e Administrativo da Faculdade Nacional de Direito - FND/ UFRJ e Docente de Elementos de Direito Constitucional na Faculdade de Direito da Universidade de Buenos Aires (UBA). Advogada. 
Resumo: No presente trabalho investigou-se de que modo o discurso punitivo anticorrupção, que ensejou a formação de forças-tarefa do Ministério Público Federal, tem o potencial de comprometer a função normativa constitucional do Ministério Público como instituição de garantia. A hipótese original é a de que as forças-tarefas ensejam um conflito entre os esforços para persecução da corrupção e os direitos fundamentais estabelecidos pela Constituição. Por conta disso, apresentam potencial de instrumentalização política, comprometendo a vocação constitucional do Ministério Público. A investigação será normativa e crítica. A metodologia será a da abordagem teórica, numa perspectiva hipotético dedutiva e terá fontes bibliográficas, mas também documentais produzidas pelo próprio Ministério Público Federal.

Palavras-Chave: Ministério Público; forças-tarefas; corrupção.

ABSTRACT: In this work we investigated how the punitive anti-corruption discourse, which fostered the formation of task forces of the Federal Brazilian Agency for Law Enforcement and Prosecution of Crimes (Federal Prosecution Service), has the potential to compromise the constitutional normative function of this Agency as an institution of guarantees. The original hypothesis is that the task forces bring about a conflict between the efforts to pursue corruption and the fundamental rights established by the Constitution. Because of this, they present potential for political instrumentalization, compromising the constitutional vocation of the Brazilian Agency for Law Enforcement and Prosecution of Crimes. The investigation will be normative and critical. The methodology will be the theoretical approach, from a hypothetical deductive perspective and will have bibliographic sources, but also documentary produced by the Federal Brazilian Agency for Law Enforcement and Prosecution of Crimes (Federal Prosecution Service).

KeYwords: Federal Prosecution Service; task forces; corruption.

SUMÁRıo: Introdução; 1. Um novo Ministério Público com dupla institucionalidade: titular a ação penal e defensor do povo; 2. A constitucionalização do político: uma crítica a subtração do poder; 3. A luta contra a corrupção: a convergência discursiva de funções antagônicas; 4. Mais poderes, menos controle; Considerações finais; Referências. 


\section{INTRODUÇÃO}

A Constituição Federal de 1988 estabeleceu uma nova institucionalidade para o Ministério Público, mudando radicalmente suas funções precípuas de atuação, efetuando, normativamente, o deslocamento de suas atribuições dando-lhe autonomia e poder. Também houve o fortalecimento da independência da instituição em relação aos poderes constituídos, assim entendidos os três poderes, executivo, legislativo e judiciário independentes e harmônicos entre si na forma do art. $2^{\circ} \mathrm{da}$ CF. A Constituição Federal brindou, ainda, seus membros de prerrogativas funcionais para não lhes sujeitar subordinação a nenhum interesse constituído, justamente para permitir o avanço do papel do Ministério Público como instituição de defesa dos direitos humanos e da democracia.

Essa importante modificação institucional produzida pela Constituição Federal de 1988, balizada pelo comando normativo constitucional, merece ser investigada de forma crítica e com uma abordagem que permita mapear sua atuação desde então, em especial no que diz respeito à sua função institucional prevista no art. 129, II, da Constituição Federal, ou seja, a obrigação de zelar pelo efetivo respeito dos Poderes Públicos e dos serviços de relevância pública aos direitos assegurados na Constituição, promovendo as medidas necessárias à sua garantia e contradição dessa função, com aquela preconizada no art. 129, I, da Constituição de dotar ao Ministério Público a titularidade da ação penal e a consequente necessidade de instrumentalização, através de ações e medidas do discurso punitivo do Estado, ou persecução penal.

Analisar se a função do Ministério Público de assegurar e zelar pelos direitos fundamentais, como defensor do povo, é compatível com a sua outra função institucional de ser o titular da ação penal pública, prevista no art. 129, I, da Constituição Federal, é tarefa complexa e precisa ser inserida no contexto da atuação da instituição nos anos que se seguiram a 05 de outubro de 1988 , uma vez que a conformação de uma única instituição com essas duas características é experiência peculiar do modelo constitucional brasileiro, pós 1988 .

É fundamental refletir de que modo se pode, no contexto normativo constitucional, impor o devido controle social à atividade institucional do Ministério Público, em especial quando essa instituição de poder 
exerce a função de defensor do povo e da democracia, todavia violando a proteção de direitos humanos, através do uso do discurso punitivo, notadamente no que diz respeito ao combate à corrupção, transformando a defesa dos direitos humanos e respeito às garantias dos cidadãos, em discurso de proteção do crime contra a sociedade.

A atuação do Ministério Público, amparada nesse discurso de proteção da sociedade, foi estendida no âmbito processual penal para além de suas funções acusatórias de titular privativo da ação penal. Três décadas após a nova configuração constitucional do Ministério Público ter se estabelecido, a instituição assumiu também funções investigativas, que terminaram por criar as chamadas Forças-Tarefas, para instrumentalizar a persecução criminal, dando a elas apoio e prioridade institucional.

O problema de pesquisa que se pretende investigar é: seriam as Forças-Tarefas instrumentos legítimos de investigação diante das garantias constitucionais? Secundariamente, há uma instrumentalização política das Forças-Tarefas na investigação dos crimes de corrupção?

A hipótese original com a qual se trabalhará será a de que as Forças-Tarefas ensejam um conflito entre os esforços para persecução da corrupção e os direitos fundamentais estabelecidos pela Constituição. Por conta disso, apresentam potencial de instrumentalização política, especialmente a depender de sua regulamentação, o que pode comprometer a vocação normativa do Ministério Público como instituição de garantias, de defesa da democracia e dos direitos humanos.

A investigação será normativa e crítica. E se concentrará na abordagem exclusivamente da questão junto ao Ministério Público Federal. A metodologia será a da abordagem teórica, numa perspectiva hipotético dedutiva, terá fontes bibliográficas e documentais produzidas pelo próprio Ministério Público Federal, em especial os relatórios de transparência institucional e dados estatísticos da instituição constantes do portal http://www.transparencia.mpf.mp.br/ ${ }^{3}$ e o Manual de Atuação sobre as Forças-Tarefas da Escola Superior do Ministério Público da União, desenvolvido em 2011, por Januário Paludo, Carlos Fernando dos Santos Lima

3 A integralidade dos relatórios está disponível em: <http://www.transparencia.mpf.mp.br/conteudo/atividade-fim/estudos-e-levantamentos-estatisticos-da-atuacao> Acesso em 12 set. 2020. 
e Vladimir Aras, sob a coordenação do primeiro. Não se trata de uma investigação sobre a atuação das Forças-Tarefas do Ministério Público Federal, mas sobre documentos oficiais institucionais.

\section{Um novo Ministério Público com dupla institucionalidade: TITULAR DA AÇÃO PENAL E DEFENSOR DO POVO.}

A Constituição Federal de 1988 ampliou enormemente as competências e atribuições do Ministério Público, modificou fortemente sua estrutura e lhe atribuiu uma nova institucionalidade.

Sob a égide da Constituição de 1967 o Ministério Público compunha o Poder Judiciário, na forma do art. 137 daquela Carta. Não dispunha a referida norma, qual seria o papel do Ministério Público, relegando à lei infraconstitucional a sua organização. Com a Emenda Constitucional $\mathrm{n}^{\circ}$ 1/69 o Ministério Público passou a ser parte do Poder Executivo, na forma no então novo art. 94, mantendo-se a redação de delegar à lei a organização da instituição e suas competências ${ }^{4}$.

O Ministério Público além da titularidade da ação penal desempenhava a função de advogado da coisa pública, com atribuição de defender a União em juízo na função de advogado público.

Por sua vez, a Lei Complementar no 40 de 1981, institucionalizou o Ministério Público com a função de ser o promotor da ação penal pública e da ação civil pública. Ainda na década de 1980, a Lei n $7347 / 85$, Lei da ação civil pública, disciplinou e ampliou, consideravelmente, as atribuições do Ministério Público ao lhe atribuir competências para tutelar os interesses difusos e coletivos e lhe deu legitimidade processual para tanto.

4 Dentre as primeiras reformas da Constituição de 1946, já sob o regime militar após o golpe de 1964, está a emenda constitucional n. 16/65 que estabeleceu uma importante competência constitucional ao Procurador Geral da República que foi a de ser o único legitimado para a propositura da representação de inconstitucionalidade de lei. Nitidamente o proposito dessa norma era tirar do congresso a palavra final sobre a normatividade das políticas públicas e dos direitos, uma vez que o art.126 da Constituição 1946 impunha que a nomeação do Procurador-Geral da República, chefe do Ministério Público, seria feita pelo Presidente da República e que a exoneração do cargo poderia ser feita ad nutum. 
Entretanto, foram os debates sobre a necessidade de fortalecimento das instituições democráticas na Assembleia Nacional Constituinte ${ }^{5}$ que impulsionaram a radical modificação das competências e da institucionalidade do Ministério Público.

Num primeiro momento, o anteprojeto apresentado pela comissão chefiada por Afonso Arinos de Mello Franco propôs o retorno da institucionalidade do Ministério Público a uma parte do poder judiciário, nos moldes da fórmula original da Constituição de 1967, antes da Emenda Constitucional $n^{\circ} 1 / 69$. Nos debates constituintes, no entanto, ganhou força a tese que prevaleceu no texto, de que o Ministério Público deveria se dissociar radicalmente dos três poderes constituídos (Judiciário, executivo e legislativo) deveria deixar de ser órgão auxiliar dos poderes e deveria exercer funções e atribuições para fiscalização da execução das leis, para sobrevivência das instituições democráticas e controle do exercício dos poderes.

Para isso, a primeira medida tomada foi criar a Advocacia Geral da União com obrigações de defesa em juízo da União, liberando o Ministério Público dessa função.

Como segunda medida deu-se status constitucional às funções da instituição, remodelando sua institucionalidade, para criar um Ministério Público, autônomo e independente, com competências criadas pela Constituição (e não por mera lei) cumulando a sua titularidade da ação penal pública (art. 129, I) com a função de controlador dos poderes públicos para proteção do patrimônio público e social, o meio ambiente e de outros interesses difusos e coletivos. Ganhou, o Ministério Público, verdadeira atribuição de ser o grande defensor do povo ${ }^{6}$.

Em outras palavras, a Constituição Federal modificou radicalmente o status do Ministério Público e criou-lhe institucionalmente uma dualidade, a saber, a de zelar pela coisa pública, pela democracia

5 As informações aqui constantes são retiradas do amplo debate da Assembleia Nacional Constituinte em torno da institucionalização do Ministério Público constantes das atas da assembleia. Disponíveis em https://www.senado.leg. br/publicacoes/anais/asp/CT_Abertura.asp

6 MAZZILLI, Hugo N. Manual do Promotor de Justiça. São Paulo: Saraiva, $2^{\text {a }}$ ed., 1991, p.113. 
e direitos humanos e ao mesmo tempo impulsionar as medidas punitivas e repressivas.

Se de um lado a vocação histórico institucional do Ministério Público para perseguir com vistas à punição de um delito se mantém, de outro lado, parece que a Constituição Federal quis que o Ministério Público abrisse outra frente de atuação, não repressiva e punitiva, mas de controle e fiscalização, para que os delitos contra o patrimônio, o ambiente e os direitos difusos e coletivos não venham sequer a ocorrer. É o Ministério Público como garante ou defensor, o responsável por proteger patrimônio, meio ambiente e direitos coletivos e difusos da atuação potencialmente danosa, quer dos particulares quer dos poderes públicos. Portanto, o Ministério Público constitucional representa uma instituição de garantia dos direitos fundamentais, garante a tutela destes, quando ocorrem as disfunções políticas por parte dos Poderes ${ }^{7}$.

Assim, além das tradicionais funções acusatórias, a Constituição Federal de 1988 estabeleceu a possibilidade de manejar ações para a tutela dos direitos fundamentais e, em particular, dos direitos sociais, bem como dos interesses públicos e dos bens constitucionais violados pelos próprios poderes públicos, ampliando consideravelmente suas funções.

Portanto, o Ministério Público atua como uma instituição independente, autônoma e especializada de garantia dos direitos, da ordem jurídica e do regime democrático, justamente por isso, a doutrina defende, segundo os dizeres de Hermes Zanetti Júnior ${ }^{8}$, que o Ministério Público é um "órgão autônomo de tutela do interesse público".

Portanto, a Constituição Federal de 1988 localiza e empodera o Ministério Público, como grande função essencial à administração da justiça, destinando a ele um papel de controle jurídico e técnico das atividades de condução da política exercida pelos poderes políticos constituídos

7 ZANETI, Hermes. CPC/2015: O Ministério Público como Instituição de Garantia e as Normas. Revista Jurídica Corregedoria Nacional: A Atuação Orientadora das Corregedorias do Ministério Público, volume II/ Conselho Nacional do Ministério Público. Brasília: CNMP, 2017, p. 107 e ss.

8 ZANETI, Hermes. CPC/2015: O Ministério Público como Instituição de Garantia e as Normas. Revista Jurídica Corregedoria Nacional: A Atuação Orientadora das Corregedorias do Ministério Público, volume II/ Conselho Nacional do Ministério Público. Brasília: CNMP, 2017, p. 113. 
(executivo, como administração pública, legislativo e judiciário), tornando o Ministério Público brasileiro uma verdadeira instituição de garantia9 .

\section{A CONSTITUCIONALIZAÇÃo do POLÍTICO: UMA CRÍTICA À SUBTRAÇÃO DO PODER}

O processo de constitucionalização do político aparece na doutrina norte-americana, onde o Estado nasce com a Constituição ${ }^{10}$. Esse processo é conhecido na doutrina do constitucionalismo como paradoxo da democracia constitucional liberal ${ }^{11}$. Esse paradoxo se constitui, porque, democracia significa autogoverno do povo, isto é, o poder que tem o povo de estabelecer as normas da organização política sob as quais recaem suas opções fundamentais. Do produto dessas decisões políticas fundamentais se extrai a Constituição, como norma base do sistema jurídico, que controla o exercício dos poderes e a produção das demais normas do sistema ${ }^{12}$.

Portanto, é o produto da democracia, isto é, a Constituição quem acaba por impor limites jurídicos às decisões democráticas do povo ao estabelecer os procedimentos e limites jurídicos ao exercício da democracia do povo. Nesse sentido, o constitucionalismo se funda na ideia de que a Constituição, como salvaguarda dos princípios fundadores, vincula as gerações futuras, inclusive em relação ao exercício do poder democrático ${ }^{13}$.

9 FERRAJOLI, Luigi. Para um Ministério Público como instituição de garantia. Revista do Ministério Público. 153: janeiro a março de 2018. P. 09.

10 Aqui apresenta-se o conceito de constituição de Thomas Paine que é o senso comum de todo constitucionalismo moderno a partir da famosa frase de Paine "in America the law is King”, estudada por todos os autores de direito constitucional.

11 HOLMES, Precommitment and the paradox of democracy. In Passions and Constraints. Chicago: University of Chicago Press, 1995 p. 150.

12 FERRAJOLI, Luigi. La democracia a través de los derechos. El constitucionalismo garantista como modelo teórico y como proyecto político. Madrid: Trotta, 2014 p.79.

13 HOLMES, Precommitment and the paradox of democracy. In Passions and Constraints. Chicago: University of Chicago Press, 1995 p. 150. 
No entanto, essa possibilidade de auto vinculação e de restrição da vontade majoritária das gerações futuras é contestável se vista desde a perspectiva da teoria da democracia, em especial se tomadas as versões procedimentais ou majoritárias de democracia, ou seja, toda e qualquer pretensão de controlar a decisão tomada pelo procedimento democrático que extrapole os próprios requisitos mínimos para o funcionamento da democracia seria injustificável ${ }^{14}$.

O caráter político da Constituição é reduzido a uma instância jurídica como forma de extensão ideológica do liberalismo político ${ }^{15}$.

Assim, o conteúdo político da Constituição se comprime e se transforma em um conteúdo jurídico. O conteúdo político da Constituição se transforma em uma interpretação de regras jurídicas convencionais e isso dá ensejo a um enraizamento corporativo da linguagem constitucional, de modo que apenas os juristas podem operar dentro do conteúdo político, que é capturado pelo discurso do jurídico ${ }^{16}$.

Tal modelo garante um absoluto controle social e político sobre as zonas de conflito que são indiscutíveis e sobre as bases empíricas do discurso constitucional. Essa transformação do conteúdo político em conteúdo jurídico evita a interação política e frustra as formações populares, o que inviabiliza a democracia, já que criptografa a linguagem, de modo que as decisões políticas fundamentais através de uma linguagem constitucional se tornam acessível apenas aos titulares do conhecimento jurídico ${ }^{17}$.

14 Essa é a concepção de Thomas Jefferson desenvolvida por toda doutrina do constitucionalismo para fazer a crítica democrática do constitucionalismo liberal. Essa visão jeffersoniana é analisada de forma contemporânea por todos os autores que trabalham o direito constitucional contemporâneo como John Hart Ely, Jeremy Waldron, Richard Bellamy, Larry Kramer, John Elster, Richard Dahl. No Brasil, por todos VIEIRA. Oscar Vilhena. A Constituição e sua reserva de justiça. Um ensaio sobre os limites materiais ao poder de reforma. São Paulo: Malheiros, 1999, em especial nas páginas 21 e seguintes, SCHMITT Carl. O Conceito do Político. Petrópolis: Vozes, 1992, p. 42. KRAMER, Larry. The people themselves. Oxford: Oxford University Press, 2004. (Kindle)

17 MÉNDEZ HINCAPÍE, Gabriel y SANÍN RESTREPO, Ricardo. "La Constitución encriptada. Nuevas formas de emancipación del poder global”. Revista de Derechos Humanos y Estudios Sociales, UASLP-UAA-US, no. 8, julio - diciembre 2012, p. 118. 
O primeiro propósito dessa criptografia é a dissimulação e subtração de todas as dimensões de poder, pois, as manifestações sensíveis de poder são ininteligíveis e indecifráveis para todos aqueles que não compartilham o conhecimento da linguagem de tomada de decisão e as chaves da criptografia, que se tornam eminentemente jurídicas. E, nesse sentido, se verifica a constitucionalização do político, entregando o manejo do poder não mais ao povo, mas aos titulares do conhecimento técnico jurídico ${ }^{18}$.

Numa certa medida é isso que ocorre ao se transferir a um ator jurídico, isto é, ao Ministério Público, o controle jurídico da atividade política, disfarçado na conformação normativo constitucional de um Ministério Público como instituição de garantias dos direitos fundamentais. Veja-se que através do discurso jurídico criptografado várias são as manifestações de membros do ministério público de modo a dar suporte ao discurso da impunidade, da morosidade e do clamor social para dar publicidade à pauta da expansão do discurso punitivo ou de pautas de interesse da instituição, como a aprovação de instrumentos de justiça negocial ${ }^{19}$.

Assim, é cediço que o controle político pelo jurídico feito pelo Ministério Público também pode se dar pela atribuição do inciso I, do artigo 129, da Constituição que estabelece o Ministério Público como titular da ação penal pública. Essa função persecutória e punitiva típica do direito penal é, por vezes, utilizada como controle pelo direito penal das políticas, quer a atividade política, quer as políticas públicas e dos grupos a elas destinado. Não se deve deixar de lembrar as críticas sobre o uso do direito penal da emergência ou processo penal de emergência, para caracterizar as práticas punitivas crescentes e violadoras de uma legalidade ${ }^{20}$.

18 MÉNDEZ HINCAPÍE, Gabriel y SANÍN RESTREPO, Ricardo. "La Constitución encriptada. Nuevas formas de emancipación del poder global". Revista de Derechos Humanos y Estudios Sociales, UASLP-UAA-US, no. 8, julio - diciembre 2012, p. 119.

19 MENDES, Soraia R. Editorial dossiê "Colaboração premiada e justiça criminal negocial": novos e múltiplos olhares. Revista Brasileira de Direito Processual Penal, Porto Alegre, vol. 3, n. 1, p. 31-38, jan./abr. 2017. p. 33.

20 FERRAJOLI, Luigi. Direito e razão: teoria do garantismo penal. Tradutores Ana Paula Zomer Sica, Fauzi Hassan Choukr, Juarez Tavares e Luiz Flávio Gomes. $4^{\mathrm{a}}$ ed. São Paulo: Ed. Revista dos Tribunais, 2002, p.650 e ss. 
Ou, de modo mais estrutural, no uso dessa importante instituição jurídica para pôr em prática uma espécie de plano de ação que translada a atores jurídico-políticos, no caso o Ministério Público, uma política de soberania baseada na decisão do uso do poder de dizer quem deve morrer e quem deve viver, naquilo que ficou amplamente conhecida como a teoria de Achille Mbembe da necropolitica ${ }^{21}$.

E nesse sentido, ao conjugarmos a técnica da atribuição do poder de decisão de vida e de morte de quem deve estar enquadrado como sujeito do direito penal, com a criptografia jurídica das categorias políticas fundamentais é possível dizer que, escondida na roupagem da democracia constitucional e numa institucionalidade nova, é necessário discutirmos que modelo de instituição de garantias o Ministério Público se constituiu, ao longo desses anos de remodelagem que ocorreram a partir da Constituição de 1988.

Dito isso, é importante verificar que se trata de uma instituição dotada de uma extensa e complexa série de atribuições que não se restringe ao órgão da acusação penal pública. O art. 129 da Constituição lhe atribui série de funções institucionais relevantes, a saber: a) o exercício da ação penal; b) a promoção do respeito dos direitos dos cidadãos, por meio de uma espécie de controle da atividade da Administração Pública; c) a promoção da ação civil pública para a proteção do patrimônio público e social, do meio ambiente e de outros interesses difusos e coletivos (como os direitos dos consumidores, das minorias e etc); d) as ações do controle de constitucionalidade; e) a defesa dos direitos e dos interesses das populações indígenas; f) o controle externo da atividade policial, etc. Assim, essa complexa estrutura organizativa para dar conta de suas atribuições constitucionais de cuidar de diversas frentes, que vão desde meio ambiente e o patrimônio público, dos direitos dos indígenas e, principalmente, a instituição e organização de forças-tarefas para combate da criminalidade.

Trata-se, em suma, de uma instituição vocacionada para ser uma instituição de garantia de direitos fundamentais: uma instituição de garantia, precisamente, dos direitos sociais e do estado social de direito

21 MBEMBE, Achille. Necropolitics. Public Culture, Volume 15, Number 1, Winter 2003, p. 71. 
da democracia. Essa vocação é a sua parametrização normativa constitucional, fruto da nova institucionalidade constitucional.

Entretanto, pode-se identificar que o Ministério Público ao investir no discurso punitivo como carro chefe de sua atuação, em especial no discurso de combate à corrupção, desafia a função institucional prevista no art. 129, II, da Constituição de ser defensor do povo e se converte em ator político do discurso punitivo em combate a todos os cânones do constitucionalismo liberal garantista, numa democracia constitucional.

Essa configuração de um "agente político da lei"22 para analisar os problemas surgidos pela ampliação da institucionalidade do Ministério Público é devidamente investigada, já há muito tempo, pela ciência política, em especial pela pesquisa empírica de Rogério Bastos Arantes, que comprova, já na metade dos anos 90 e início dos anos 2000, a vocação política da instituição. Arantes, em recente artigo de opinião questiona sobre a "jabuticaba" que se tornou a instituição e a necessidade de repensar, em termos institucionais, quem irá cuidar do "barraco" que se tornou o Ministério Público ${ }^{23}$.

O exemplo claro dessa patologia de conflito institucional aparece quando a instituição quer se ver reconhecida pela população pelo seu discurso punitivo, como o das mega operações criminais ou quando seus membros produzem manifestos de cunho político para "alertar" a população sobre a necessidade de se incorporar no discurso político o chamado populismo penal ${ }^{24}$. Também é um sintoma desse conflito quando a instituição faz campanhas publicitárias para pressionar os poderes políticos com suas pautas de combate a corrupção. Veja-se aqui como

\footnotetext{
22 ARANTES, Rogério Bastos. Ministério Público e Política no Brasil. São Paulo: Editora Sumaré, 2002. P.301.

23 ARANTES, Rogério Bastos. Quem vai cuidar da jabuticaba que virou barraco?. Época on line, 07.08.2019. disponível em <https://epoca.globo.com/ rogerio-arantes/coluna-quem-vai-cuidar-da-jabuticaba-que-virou-barraco-23861102> Acesso em 31 de julho de 2020.

24 Sobre populismo penal, por todos: GLOECKNER, Ricardo Jacobsen; RAMOS, Marcelo Butelli. Os sentidos do populismo penal: Uma análise para além da condenação ética. DELICTAE: Revista de Estudos Interdisciplinares sobre o Delito, [S.1.], v. 2, n. 3, p. 248, dez. 2017.
} 
exemplo a campanha institucional das "dez medidas contra corrupção", que possui um site de divulgação de propaganda institucional, hospedado no domínio oficial do MPF, inclusive com venda de material publicitário em apoio a campanha ${ }^{25}$.

Também chama bastante atenção que a prioridade institucional do Ministério Público Federal, exposta em vários de seus documentos internos e de transparência institucional, é exclusivamente o combate a corrupção ${ }^{26}$. Os documentos produzidos pela própria instituição revelam a tendência a priorizar o discurso anticorrupção como carro chefe de atuação. O Ministério Público Federal conta com um portal de transparência ${ }^{27}$ e nos relatórios de resultados do Procurador-Geral da República, que versam sobre estatísticas, transparência, profissionalismo e efetividade, constantes do portal, é possível verificar que a partir do ano de 2013, até o último relatório apresentado que é de 2017, a prioridade institucional do Ministério Público Federal é o combate a corrupção, inclusive, através do uso de campanha em redes sociais com a hashtag corrução não (\#corrupcaonao).

O relatório de transparência de $2011 / 2013^{28}$ dá como prioridade institucional a governança aplicada ao setor público baseado na eficiência, accountability, transparência e probidade. Afirma a necessidade do planejamento estratégico do MPF e ressalta que a grande estratégia de afirmação da instituição é apresentar o planejamento para o período compreendido entre 2011 e 2020. Por sua vez, nos objetivos do Planejamento Estratégico

25 Disponível em http://www.dezmedidas.mpf.mp.br.

26 Brasil, Ministério Público Federal. Relatório de resultados do Ministério Público Federal: 2013 / 2015: diálogo, unidade, transparência, profissionalismo, efetividade / coordenação Lauro Pinto Cardoso Neto. - Brasília: MPF, 2015, p. 18.

27 No portal da transparência podem ser consultados todos os dados públicos e estatísticos de atual institucional do MPF. Nesse portal são publicados os relatórios de gestão da instituição e suas prioridades institucionais. Os dados podem ser conferidos em http://www.transparencia.mpf.mp.br/conteudo/ atividade-fim/estudos-e-levantamentos-estatisticos-da-atuacao

28 BRASIL, Ministério Público Federal. Governança, gestão, inovação e resultados: biênio 2011- 2013. - Brasília: MPF, 2013. P. 21. Disponível em < http:// www.mpf.mp.br/o-mpf/sobre-o-mpf/gestao-estrategica-e-modernizacaodo-mpf/sobre/publicacoes/pdf/relatorio_de_gestao_bienio_2011_2013. pdf > . Acesso em 30.07.2020. 
Institucional ${ }^{29}$, no número de 25 , estabelece o fortalecimento de todas as funções institucionais, normativo constitucionais, do MPF. Existe no objetivo n. 18 uma intenção para atuação institucional de "Fortalecer e desenvolver o exercício do poder investigatório, aprimorando, inclusive, o controle externo da atividade policial. O MPF deve se tornar sujeito ativo da definição de suas prioridades de atuação, instaurando e conduzindo procedimentos investigatórios”, o que, normativamente é contestável como atribuição constitucional do Ministério Público.

Entretanto, a partir do relatório de transparência institucional de $2013 / 2015^{30}$, seguido pelos relatórios de transparência de 2015/2016 $6^{31}$ e $2015 / 2017^{32}$, percebe-se uma mudança radical da prioridade institucional do MPF para estabelecer que o combate a corrupção, a operação lava a jato e as dez medidas contra corrupção compõem as prioridades institucionais máximas do MPF, ainda que no planejamento estratégico essas atividades não tenham ganhado nenhum destaque, de modo prevalente em relação aos demais objetivos institucionais. De fato, o combate a corrução é o objetivo institucional n. 21, que diz, suscintamente, "combate à

29 Os objetivos do Planejamento Estratégico Institucional para o MPF para o período de 2011 a 2020 encontra-se disponível em < http://www.mpf.mp.br/o-mpf/ sobre-o-mpf/gestao-estrategica-e-modernizacao-do-mpf/planejamento-estrategico/planejamento-estrategico-institucional-2011-2020/objetivos-estrategicos-separados-por-perspectivas.pdf> . Acesso em 30.07.2020.

30 BRASIL, Ministério Público Federal. Relatório de resultados do Ministério Público Federal: 2013 / 2015: diálogo, unidade, transparência, profissionalismo, efetividade. Brasília: MPF, 2015. Disponível em http://www.mpf.mp.br/o-mpf/sobre-o-mpf/gestao-estrategica-e-modernizacao-do-mpf/sobre/publicacoes/pdf/002_15_relatorio_de_resultados_final_online-compressed.pdf. Acesso em 30.07.2020.

31 BRASIL. Ministério Público Federal. Relatório de resultados do Procurador-Geral da República: diálogo, unidade, transparência, profissionalismo, efetividade: 2015-2016. Brasília: MPF, 2016 disponível em <http://www.mpf.mp.br/o-mpf/sobre-o-mpf/gestao-estrategica-e-modernizacao-do-mpf/sobre/publicacoes/pdf/RelatoriodeResultadosdoPGR_20152016.pdf>. Acesso em 30.07.2020.

BRASIL. Ministério Público Federal. Relatório de resultados do Procurador-Geral da República: diálogo, unidade, transparência, profissionalismo, efetividade: 2015-2017. Brasília: MPF, 2017. Disponível em http://www.mpf.mp.br/o-mpf/sobre-o-mpf/gestao-estrategica-e-modernizacao-do-mpf/sobre/publicacoes/pdf/relatorio-gestao-pgr-2015-2017.pdf. Acesso em 30.07.2020. 
criminalidade e à corrupção, assegurar, na defesa da sociedade, a apuração e a persecução célere e eficaz dos ilícitos penais e dos atos de improbidade administrativa, reduzindo a impunidade e a incidência de condutas criminosas e ímprobas"33 , não fazendo qualquer referência a operação lava a jato, por exemplo, e que ganha alta prioridade institucional no período que vai de 2013 até 2017, último relatório de transparência e estatística institucional disponível no portal, na data da última consulta ocorrida em 30 de julho de 2020.

Além disso, no relatório de gestão apresentado ao Tribunal de Contas da União, com a prestação de contas anual da instituição para o ano de 2015, também se verifica a mesma prioridade institucional que nos documentos de transparência, quando, já na introdução se verifica ${ }^{34}$ :

"O presente relatório destaca o avanço do Ministério Público Federal (MPF) no combate à corrupção e na profissionalização da sua gestão, com o amadurecimento das metodologias de gerenciamento de projetos e de redesenho dos seus processos de trabalho. Em 2015, foram mais de 25 milhões investidos em 27 projetos administrativos e 48 finalísticos, que contaram com a participação de 321 membros do MPF e 588 servidores. O trabalho contra a corrupção foi intensivo. Somente com a Força-Tarefa da Lava Jato retornaram, até setembro de 2015 , cerca de $\mathrm{R} \$ 2$ bilhões à sociedade brasileira, além do bloqueio de mais de 400 milhões de francos suíços, fruto da cooperação internacional relativa ao caso. Cada investimento no MPF, seja na área criminal, seja na área cível, tem retornado como resultados à sociedade. Destacase ainda a unidade dos ministérios públicos do Brasil e de países iberoamericanos em torno da campanha \#CORRUPÇÃONÃO, coordenados pelo Procurador-Geral da República”.

Portanto, dos documentos produzidos pela própria instituição, para efeitos discursivos, o Ministério Público Federal não quer se

33 A referência normativa do Planejamento estratégico institucional são as Portarias PGR/MPF n ${ }^{\circ}$ 687, de 20/12/2011 e Portaria PGR/MPF n 687, de 20/12/2011.

34 O Relatório encontra-se em <http://www.transparencia.mpf.mp.br/transparencia/conteudo/execucao-orcamentaria-e-financeira/prestacao-de-contas -anual/2015/relatorio-de-gestao-mpf_2015.pdf> Acesso em 30.07.2020. 
apresentar como uma instituição de garantias dos direitos fundamentais, de controle e de manutenção do Estado Democrático de Direito, como parece ser sua nova vocação normativo constitucional, no desenho feito pela Constituição de 1988, mas como sendo uma agência pública de combate à corrupção e de persecução penal ${ }^{35}$.

Assim, quando os atores públicos que recebem atribuição constitucional de garantidores dos direitos do povo, dos direitos fundamentais e da democracia desviam a função para chamar a população a aderir a um discurso punitivo, por vezes, violador dos direitos fundamentais constitucionais e convencionais, o que se tem é uma ruptura das garantias da Constituição operadas, não pelos agentes criminosos ou por outros atores sociais, mas pelos próprios agentes públicos empoderados constitucionalmente e pertencentes a uma instituição de garantias como o Ministério Público ${ }^{36}$.

Portanto, peças publicitária institucionais no Ministério Público Federal, como se vê da página que vende camisetas das medidas anticorrupção, contratação de assessoria de imprensa para comunicação na mídia sobre as mega operações criminais protagonizadas pelos membros do Ministério Público ou o "manifesto anti-bandidolatria" ${ }^{37}$, são facetas institucionais de um ministério público que abriu mão da democracia constitucional garantistas e, portanto, de suas funções normativamente delineadas ${ }^{38}$.

35 Do manual de Traduções oficiais do MPF, conforme Portaria PGR/MPF no 618, se vê que a indicação de tradução da instituição "Ministério Público Federal” para inglês é Federal Prosecution Service, que literalmente é serviço de acusação, aqui optou-se por utilizar a expressão Law Enforcement and Prosecution of Crimes (Federal Prosecution Service) para significar Ministério Público Federal, justamente porque o objetivo é apresentar o compromisso normativo da parametrização da institucionalidade constitucional pós 1988 , onde o ministério público não é mais apenas um ministério Público de persecução criminal, mas a instituição de defensor do povo e da democracia. Esse é justamente o objeto da presente pesquisa.

36 FERRAJOLI, Luigi. Para um Ministério Público como instituição de garantia. Revista do Ministério Público. 153: janeiro a março de 2018. P. 26.

37 O manifesto circula em vários sites pelas redes sociais, sua integra pode ser consultada em https://www.defesanet.com.br/ghbr/noticia/26662/ Manifesto-contra-a-BANDIDOLATRIA-/

38 Alerta Marcos Alan Gomes sobre o papel da mídia, da informação e da comunicação na construção da realidade social. Em Mídia e Sistema Penal: as 
Além disso, é essencial analisar os documentos institucionais que configuram orientações para as práticas institucionais, para além do discurso à população. Parte dessas orientações institucionais que indicam a prevalência da função penal, em detrimento da função de defensor do povo e da democracia, é a organização do Ministério Público, sobretudo o federal, em forças-tarefa de atuação, baseadas na instrumentalização prática institucional do discurso de combate a corrupção.

\section{A LUTA CONTRA A CORRUPÇÃO: A CONVERGÊNCIA DISCURSIVA DE FUNÇÕES ANTAGÔNICAS}

Para além dos poderes de defensor do povo e de titular da ação penal pública, a luta contra a corrupção foi um discurso de que se utilizou o Ministério Público, sobretudo o federal, para atrair para si mais funções do que a própria Constituição outorgou.

Fundado nos instrumentos internacionais conhecidos, como Convenção de Palermo e Convenção de Mérida, bem como nas experiências de investigação por grupos de instituições internacionais e nacionais, a Escola Superior do Ministério Público da União, criou em 2011 o Manual de Atuação sobre as Forças-Tarefas, por Januário Paludo, Carlos Fernando dos Santos Lima e Vladimir Aras, sob a coordenação do primeiro.

O Manual indica o objetivo claro de servir de pauta de atuação e sugestão normativa para as investigações "do crime organizado e de delitos de alta complexidade, bem como de atos de improbidade administrativa" ${ }^{39}$.

Com base na Convenção de Palermo, aderida ao ordenamento nacional pelo Decreto $\mathrm{n}^{0} 5.015 / 2004$, convenção das nações unidas contra o crime organizado, que também tratava do combate à corrupção e à lavagem de dinheiro, bem como na Convenção de Mérida, aderida ao ordenamento nacional pelo Decreto $\mathrm{n}^{\circ} 5.687 / 2006$, convenção das

distorções da criminalização nos meios de comunicação. GOMES, Marcus Allan. Mídia e sistema penal: as distorções nos meios de comunicação. Rio de Janeiro: Revan, 2015 p. 62.

39 PALUDO, Januário; LIMA, Carlos Fernando dos Santo e ARAS, Vladimir. Forças-tarefas: direito comparado e legislação aplicável - MPF. Brasília: Escola Superior do Ministério Público da União, 2011. p. 19 
nações unidas contra a corrupção, os autores do Manual propõem medidas que empoderam o Ministério Público para além do que dispôs o art. 129 da Constituição.

Importante destacar que nem a Convenção de Palermo e nem a Convenção de Mérida são instrumentos internacionais com status constitucional, capazes de agregar funções institucionais de hierarquia constitucional ao Ministério Público e, também, há que se levar em conta que a força normativa equivalente a lei, dos referidos instrumentos normativos, também é contestável sob o ponto de vista da reserva de legalidade estrita ${ }^{40}$.

Por sua vez, de acordo com o art. 19 da Convenção de Palermo, reproduzido no art. 49 da Convenção de Mérida, os estados partes deverão possibilitar investigações conjuntas e, no caso de inexistência de acordos ou protocolos, poderá ser decidida casuisticamente a realização de investigação conjunta.

Ainda, o art. 20 da Convenção de Palermo, reproduzido no art. 50 da Convenção de Mérida, estabeleceram que cada estado parte, na medida em que lhe permitam os princípios fundamentais do seu ordenamento jurídico, criassem técnicas especiais de investigação como a vigilância eletrônica e de outras índoles, e operações secretas, bem como adotarem regras que autorizem a admissibilidade dessas provas perante os tribunais ${ }^{41}$.

$\mathrm{O}$ art. 26 da Convenção de Palermo e o art. 37 da Convenção de Mérida, desta vez não de forma idêntica, estabelecem que os estados partes tomarão medidas para que as pessoas que tenham tomado parte dos delitos cooperem com as autoridades competentes, com fins investigatórios e probatórios.

40 CYRILLO DA SILVA, Carolina Machado. Os quatro modelos da posição hierárquica do direito internacional dos direitos humanos nas constituições dos países da América do Sul. In: NASCIMENTO, Valéria Ribas e SALDANHA, Jania Maria Lopes. Os Direitos Humanos e o constitucionalismo: espectros da DUDH e da Constituição da república Federativa do Brasil. Rio de Janeiro: Lumen Juris, 2019. E BRASIL. Supremo Tribunal Federal. Recurso Ordinário em Habeas Corpus ${ }^{0}$ 121835. Distrito Federal. Relator: Ministro Celso de Melo. Pesquisa de Jurisprudência, Acórdãos, 23.11.2015.

41 Essas atividades acabaram basicamente sendo aderidas ao ordenamento nacional pela Lei $\mathrm{n}^{\circ} 12.850 / 2013$, inclusive sendo acrescentada a infiltração virtual de agentes pela Lei ${ }^{\circ} 13.964 / 2019$. 
Diante dessa base normativa internacional, os autores do Manual apresentaram um histórico sobre as Forças-Tarefas. Primeiramente identificaram a expressão com o uso militar que dele se faz, a partir do primeiro conceito da marinha estadunidense ${ }^{42}$.

Seguem, inspirando-se na experiência estadunidense e italiana, para reforçar que o uso da expressão Força-Tarefa se vulgarizou. Todavia, passou a ser usado como "conceito operacional que implica a mobilização de meios de mais de um órgão público, que se articulam para atingir metas submetidas a planejamento estratégico" e passou a ser considerado como meio mais efetivo de combate às organizações criminosas ${ }^{43}$.

Dedicaram boa parte do trabalho a justificar o uso das Forças-Tarefas por inspiração na Operação italiana conhecida como "Mani Pulite". Ficou muito claro que, assim como as Convenções de Palermo e de Mérida o fazem, a corrupção foi intimamente, e quase indissociavelmente, vinculada às organizações criminosas e à atuação política.

Segundo os autores:

a "Operação Mãos Limpas" se espalhou por outras procuradorias italianas, tendo como foco outros casos de malaffare in politica (corrupção política), inclusive com a prisão de Mario Chiesa, então candidato a prefeito de Milão pelo Partido Socialista Italiano, e de inúmeros outros políticos e empresários, entre eles o ex-Primeiro Ministro socialista Bettino $\mathrm{Craxi}^{44}$.

Observa-se que o fundamento utilizado pelos autores para sustentar que as investigações de crimes de corrupção, deveriam se dar

42 Distinguem task-force (Força-Tarefa) de joint task-force (Força-Tarefa conjunta), pois o primeiro se daria no âmbito de uma mesma força PALUDO, Januário; LIMA, Carlos Fernando dos Santo e ARAS, Vladimir. Forças-tarefas: direito comparado e legislação aplicável - MPF. Brasília: Escola Superior do Ministério Público da União, 2011. p. 24.

43 PALUDO, Januário; LIMA, Carlos Fernando dos Santo e ARAS, Vladimir. Forças-tarefas: direito comparado e legislação aplicável - MPF. Brasília: Escola Superior do Ministério Público da União, 2011. p. 25.

44 PALUDO, Januário; LIMA, Carlos Fernando dos Santo e ARAS, Vladimir. Forças-tarefas: direito comparado e legislação aplicável - MPF. Brasília: Escola Superior do Ministério Público da União, 2011. P. 26. 
vinculadas às investigações de organizações criminosas e, mais especificamente, direcioná-las às atividades dos agentes políticos.

Está, pois, definido o discurso punitivo enquanto voltado ao controle das atividades políticas. Trata-se de uma defesa do povo e da democracia por meio do sistema penal, aliando assim a função de defensor do povo com a de acusador exclusivo, empoderando o discurso de que o combate à corrupção é a defesa do povo e da democracia.

Com isso, o conteúdo político está reduzido ao jurídico. Mais especificamente ao jurídico-criminal, cuja criptografia, especialmente acusatória, é de conhecimento restrito e manejo privativo do Ministério Público, em verdadeira supressão da dimensão política e usurpação de uma institucionalidade que deveria, ao menos normativamente, garantir direitos fundamentais.

\section{MAIS PODERES, MENOS CONTROLE}

Invocando os exemplos brasileiros das Forças-Tarefas do Mensalão e CC- $5^{45}$, os autores passaram a defender a organização desses grupos interinstitucionais para realização de investigações mais complexas.

Os autores também chamaram atenção para a atuação do que classificaram como "grupo-tarefa estratégico e de articulação", originalmente Estratégia Nacional de Combate à Lavagem de Dinheiro, que recebeu um segundo "c" para incluir a expressão “à corrupção" antes de "à lavagem de dinheiro", daqui em diante a ENCCLA ${ }^{46}$. Este órgão definiu como meta, em 2006, "elaborar projeto de decreto disciplinando as regras gerais

45 Essa Força-Tarefa CC5 foi também conhecida como Força-Tarefa Banestado, processo judicial conduzido pelo ex-juiz Sérgio Fernando Moro, que recebeu o seguinte agradecimento no Manual: "Merece agradecimento o Juiz Federal Sérgio Fernando Moro pelas posições de vanguarda no cumprimento das normas penais e processuais penais ao longo do caso Banestado.” PALUDO, Januário; LIMA, Carlos Fernando dos Santo e ARAS, Vladimir. Forças-tarefas: direito comparado e legislação aplicável - MPF. Brasília: Escola Superior do Ministério Público da União, 2011. p. 7.

46 PALUDO, Januário; LIMA, Carlos Fernando dos Santo e ARAS, Vladimir. Forças-tarefas: direito comparado e legislação aplicável - MPF. Brasília: Escola Superior do Ministério Público da União, 2011. p. 27 e 28. 
para a alocação de recursos humanos e materiais do Poder Executivo para forças-tarefas interinstitucionais, com o objetivo de combater a

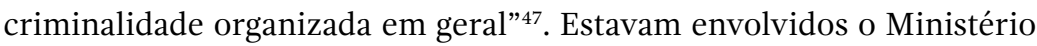
Público Federal (MPF), a Controladoria Geral da União (CGU), o Conselho Nacional de Procuradores-gerais (CNPG), a Secretaria da Receita Federal (SRF), o Ministério da Previdência Social (MPS), o Ministério da Defesa (MD), o Gabinete de Segurança Institucional (GSI), a Procuradoria Geral da Fazenda Nacional (PGFN), a Advocacia Geral da União (AGU) e o Banco Central do Brasil (BACEN).

Os autores do Manual assim definiram Força-Tarefa:

Do ponto de vista criminal, força-tarefa é a conjugação de meios materiais e recursos humanos voltada para o atendimento a necessidades temporárias, relacionada à persecução de delitos complexos, crimes graves ou infrações cometidas por organizações criminosas, sempre tendo em mira um objeto específico em determinada área geográfica ${ }^{48}$.

Na proposta realizada, a Força-Tarefa não teria prazo fixo, poderia durar tanto tempo quanto demorar a investigação, porém, "invariavelmente, uma força-tarefa funcionará de forma temporária, não permanente”, segundo preconiza o manual. ${ }^{49}$

As Forças-Tarefas não devem ter número mínimo de participantes, mas é prudente evitar um número exagerado de integrantes, porque isso dificultaria a coordenação da investigação e a manutenção do sigilo das investigações.

Ainda, a constituição de uma Força-Tarefa depende da manifestação do Procurador Geral da República e dos órgãos colegiados superiores

47 PALUDO, Januário; LIMA, Carlos Fernando dos Santo e ARAS, Vladimir. Forças-tarefas: direito comparado e legislação aplicável - MPF. Brasília: Escola Superior do Ministério Público da União, 2011. p. 28.

48 PALUDO, Januário; LIMA, Carlos Fernando dos Santo e ARAS, Vladimir. Forças-tarefas: direito comparado e legislação aplicável - MPF. Brasília: Escola Superior do Ministério Público da União, 2011. p. 28-29.

49 PALUDO, Januário; LIMA, Carlos Fernando dos Santo e ARAS, Vladimir. Forças-tarefas: direito comparado e legislação aplicável - MPF. Brasília: Escola Superior do Ministério Público da União, 2011. p. 29. 
da instituição. O Manual admite que a iniciativa parta não apenas do membro do Ministério Público com atribuição (promotor natural), mas de qualquer membro, até mesmo de órgãos externos, desde que o requerimento seja feito ao Procurador Geral. A constituição de Força-Tarefa está relacionada à transcendência, relevância ou importância da causa.

Deve haver uma formalização da relação entre os órgãos por meio de um memorando ou uma portaria conjunta, mas a coordenação do grupo deve estar sempre atribuída a um membro do Ministério Público, reservando o poder sobre a Força-Tarefa à instituição, podendo a parte executória ficar com a polícia.

No referido Manual, os autores terminam apresentando um anteprojeto de resolução sobre Forças-Tarefas e outro anteprojeto sobre sigilo processual "no âmbito de processos e feitos sigilosos que tramitem em segredo de justiça, no âmbito do Ministério Público" ${ }^{50}$.

Na prática, três eventos tiveram especial importância na efetivação do empoderamento do Ministério Público buscado pelos autores do Manual: (1) a bem-sucedida campanha de marketing institucional contra a Proposta de Emenda Constitucional 37 de 2011; (2) o julgamento do Recurso Extraordinário 593.727; (2) a aprovação e aplicação da Resolução 181/2017 no âmbito do Conselho Nacional do Ministério Público.

Na luta por espaço do exercício de poder ${ }^{51}$, na esteira das manifestações populares de junho de 2013, a Associação Nacional do Ministério

50 PALUDO, Januário; LIMA, Carlos Fernando dos Santo e ARAS, Vladimir. Forças-tarefas: direito comparado e legislação aplicável - MPF. Brasília: Escola Superior do Ministério Público da União, 2011. p. 119 e ss.

51 PRADO, Geraldo Luiz Mascarenhas. A investigação criminal e a PEC 37. Boletim IBCCRIM, São Paulo, v. 21, n. 248, p. 5-7, jul. 2013, faz importante observação sobre o realce do papel estratégico assumido pela investigação e que a votação da PEC 37 era mesmo uma questão política pertinente à democracia. Não são poucos os trabalhos que defendem a validade da investigação realizada diretamente pelo Ministério Público: MOURA, Daniela Souza Filho. A investigação criminal direta pelo ministério público em face do sistema acusatório de processo penal. Revista do Ministério Público do Estado do Pará, Belém, v. 7, n. 7, p. 43-66, 2012, a imensa maioria de membros do Ministério Público, alguns especificamente sobre a atuação do Ministério Público na investigação de crimes de corrupção: SOUZA, Artur de Brito Gueiros; CONSENTINO, Luís Cláudio Senna. Atuação do Ministério Público nas investigações de corrupção no Brasil. In: COMPLIANCE e temas relevantes de direito e 
Público (CONAMP), o Conselho Nacional de Procuradores-Gerais (CNPG), a Associação Nacional dos Procuradores da República (ANPR), a Associação Nacional do Ministério Público do Distrito Federal e Territórios (AMPDFT), a Associação Nacional dos Procuradores do Trabalho (ANPT) e a Associação Nacional do Ministério Público Militar (ANMPM) coordenaram a campanha intitulada "Brasil contra a Impunidade" ${ }^{52}$, cujo objetivo era construir a opinião contra a Proposta de Emenda Constitucional n ${ }^{\circ} 37$ de 2011, que tornava a investigação criminal atividade privativa da polícia.

Na campanha, os órgãos coordenadores afirmavam que a PEC 37 "retira o poder de investigação do Ministério Público"53, já havia sido aprovada na Comissão de Constituição e Justiça da Câmara e estava sendo encaminhada para o Plenário. Ainda em junho de 2013 a PEC 37 foi rejeitada.

O segundo evento ocorreu em 14 de maio de 2015, quando o Plenário do Supremo Tribunal Federal, por maioria de 7 a 4, negou provimento ao Recurso Extraordinário 593.727 e reconheceu o poder de investigação do Ministério Público. Muito embora o Ministério Público já viesse realizando investigações (inclusive os Ministérios Públicos estaduais, especialmente por seus GAECOs - Grupos de Atuação Especial de Combate ao Crime Organizado - espécie de Força-Tarefa estaduais), o referido recurso especial foi selecionado como representativo da controvérsia em que foi reconhecida a repercussão geral.

Portanto, esses dois eventos tornaram o poder de investigação do Ministério Público legítimo, na medida em que tal atividade não estava expressa no art. 129 da Constituição e, portanto, foram somas às atribuições constitucionais ampliando os poderes do ministério público.

Todavia, não havia qualquer regulamentação legal, seja da atividade investigatória do Ministério Público, seja das Forças-Tarefas. Por

processo penal: estudos em homenagem ao advogado e professor Felipe Caldeira. Organização de Bruno Espiñeira LEMOS et al. Belo Horizonte: D’Plácido, 2018, p. 139-153.

52 Disponível em <https://www.cnmp.mp.br/portal/institucional/3-noticias/ todas-as-noticias/2066-brasil-contra-a-impunidade667>. Acesso em 08 jun 2020.

53 Disponível em <https://www2.mppa.mp.br/sistemas/gcsubsites/index. php?action=MenuOrgao. show\&id=3828\&oOrgao=76>. Acessado em 08 jun 2020 . 
isso o terceiro evento foi fundamental, não para que o Ministério Público realizasse investigação ou que fossem constituídas as Forças-Tarefas, mas para legitimar por meio de uma regulamentação infralegal a atuação que em muito ultrapassa o estabelecimento de regras internas de atuação.

Com a Resolução $\mathrm{n}^{0} 181 / 2017$, posteriormente alterada pela Resolução no 183/2018, o Conselho Nacional do Ministério Público estabeleceu regras sobre o PIC - procedimento investigatório criminal $^{54}$, conferindo poderes investigatórios amplos ao Ministério Público. Mais do que isso, estabeleceu a possibilidade do procedimento ser instaurado por meio de força tarefa ou grupo de atuação especial. Regulamentou não apenas a atuação do Ministério Público, mas dispôs sobre publicidade e sigilo, acesso da defesa aos atos, direito das vítimas e, inclusive, sobre acordo de não persecução penal ${ }^{55}$, todas matérias de direito processual que envolvem respeito a direitos fundamentais e, portanto, reservadas à lei.

Extrai-se que o Ministério Público foi além dos dicotômicos poderes de defensor do povo e legitimado exclusivo para a ação penal. Em atuação historicamente desenvolvida, que envolveu importante campanha publicitária de construção de uma imagem institucional de confiança da opinião pública, a partir do uso de uma linguagem jurídica que funciona como a criptografia para o manejo político, o Ministério Público assumiu também as funções de investigação, sempre amparado no discurso público de que o combate à corrupção é corolário da defesa da democracia.

Dado que sua posição constitucional original a respeito da investigação era de fiscal do órgão investigador, o Ministério Público como investigador ficou sem fiscal externo dessa atividade. Assumindo também a função de legislador processual penal, foi o próprio Ministério Público quem definiu suas próprias funções e poderes no âmbito das investigações

54 Deve se frisar que o Procedimento Investigatório Criminal não foi criado pela Resolução 181/2017, ele já existia desde a edição da Resolução 13/2006 do próprio Conselho Nacional do Ministério Público. Todavia, isso ocorreu antes da decisão proferida pelo Supremo Tribunal Federal no RE 593.727 e não se regulamentava as chamadas Forças-Tarefas. Vale a leitura da crítica feita à época da inusitada criação: VIEIRA, Renato Stanziola. Procedimento investigatório criminal, esse outro desconhecido. Boletim IBCCRIM, São Paulo, v. 14, n. 168, p. 12-13, nov. 2006.

55 Que só veio a ser previsto e regulamentado em lei, por ocasião da Lei ${ }^{\circ}$ $13.964 / 2019$. 
complexas contra o crime organizado e a corrupção, em evidente ruptura do modelo constitucional de garantia ${ }^{56}$. Por fim, os instrumentos internacionais em matéria de cooperação jurídica internacional não preenchem os requisitos constitucionais para autorizar ampliação de funções tendentes a limitar direitos fundamentais, uma vez que não são tratados internacionais em matéria de direitos humanos capazes de ampliar competências institucionais definidas, exclusivamente, por normas de hierarquia constitucional.

\section{CONSIDERAÇÕES FINAIS}

Pretendeu-se questionar a legitimidade do uso das Forças-Tarefas do Ministério Público Federal para investigação criminal direta diante das garantias constitucionais, bem como se há uma instrumentalização política desse mecanismo, nos casos de corrupção. Ao final foi possível constatar que a hipótese inicial é a melhor resposta à indagação investigativa.

O objeto de análise crítica recaiu sobre a instituição do Ministério Público, que recebeu um tratamento diferenciado da tradição constitucional pela Assembleia Nacional Constituinte, dando-lhe status constitucional e poderes de atuação balizados pelas normas constitucionais.

A primeira crítica efetuada foi sobre a dupla institucionalidade do Ministério Público que ao mesmo tempo se anuncia como instituição talhada para defender os interesses coletivos do povo e a manutenção

56 É muito importante ressaltar que as técnicas especiais de investigação que se configuram como meios de obtenção de prova são cada vez mais utilizados no direito brasileiro para determinar a sorte do julgamento do caso penal, o que torna a investigação ainda mais poderosa no sistema processual que se desenha no âmbito dos processos de corrupção e criminalidade organizada. Vide: SANTORO, Antonio E. R. A imbricação entre maxiprocessos e colaboração premiada: o deslocamento do centro informativo para a fase investigatória na Operação Lava Jato. Revista Brasileira de Direito Processual Penal, Porto Alegre, vol. 6, n. 1, p. 81-116, jan./abr. 2020; MELO, Marcos Eugênio Vieira. Neoinquisitorialismo processual penal e a contaminação do julgador com os atos de investigação: a burla interna no processo penal brasileiro como obstáculo ao contraditório. Revista Brasileira de Direito Processual Penal, Porto Alegre, vol. 6, n. 2, p. 951-992, mai./ago. 2020; RIBEIRO, Marcelo H. M.; SAMPAIO, André R.; FERREIRA, Amanda A. A influência dos elementos de informação do inquérito policial na fundamentação da sentença penal condenatória: uma análise das sentenças prolatadas pelas varas criminais de Maceió/AL. Revista Brasileira de Direito Processual Penal, Porto Alegre, vol. 6, n. 1, p. 175-210, jan./abr. 2020. 
das instituições democráticas, também é o titular da força de impulsão da persecução punitiva penal estatal. Essa dualidade leva ao inevitável uso do direito penal como técnica de substituição das decisões políticas, em consequências que podem ser desde o controle social pelo direito penal até a criminalização da atividade política e das políticas públicas.

Realizou-se a análise tomando por base doutrinas críticas do modelo do constitucionalismo liberal, fundado na ideia do compromisso de transformar o político em jurídico como forma de conter abusos de poder.

Verificou-se que é possível subtrair e disfarçar um discurso político através de uma instituição jurídica, criada para zelar pela democracia e pelo controle dos poderes, portanto vocacionada para ser uma instituição constitucional de garantias.

Para tanto, além das funções constitucionalmente atribuídas de defensor do povo e acusador exclusivo na ação penal, o Ministério Público alargou seu poder para alcançar o controle das investigações sobre os atos de corrupção e criminalidade organizada, por meio do exercício abusivo da função de legislador e com o uso estratégico de campanha publicitária de alcance da opinião pública, com discurso de combate a corrupção.

Por fim, fica em aberto o questionamento de como conter o abuso do poder de quem é, juridicamente, o responsável pelo controle do poder, não havendo dúvidas que seguirá em aberto, na nossa institucionalidade constitucional a dúvida sobre quem, numa democracia, controla o controlador que acumulou as funções, inclusive, incorporando aquelas que controlava, através de normatividade infralegal artificialmente criadas interna corporis.

\section{REFERÊNCIAS}

ARANTES, Rogério Bastos. Ministério Público e Política no Brasil. São Paulo: Editora Sumaré, 2002.

ARANTES, Rogério Bastos. Quem vai cuidar da jabuticaba que virou barraco?. Época on line, 07.08.2019. disponível em <https://epoca.globo.com/rogerio-arantes/coluna-quem-vai-cuidar-da-jabuticaba-que-virou-barraco-23861102> Acesso em 31 de julho de 2020.

BRASIL, Ministério Público Federal. Relatório de resultados do Ministério Público Federal: 2013 / 2015: diálogo, unidade, transparência, profissionalismo, efetividade / Brasília: MPF, 2015. 
BRASIL. Ministério Público Federal. Relatório de resultados do Procurador-Geral da República: diálogo, unidade, transparência, profissionalismo, efetividade: 20152016. Brasília: MPF, 2016.

BRASIL. Ministério Público Federal. Relatório de resultados do Procurador-Geral da República: diálogo, unidade, transparência, profissionalismo, efetividade: 20152017.Brasília: MPF, 2017.

CYRILLO DA SILVA, Carolina Machado. Os quatro modelos da posição hierárquica do direito internacional dos direitos humanos nas constituições dos países da América do Sul. In: NASCIMENTO, Valéria Ribas e SALDANHA, Jania Maria Lopes. Os Direitos Humanos e o constitucionalismo: espectros da DUDH e da Constituição da república Federativa do Brasil. Rio de Janeiro: Lumen Juris, 2019.

FERRAJOLI, Luigi. La democracia a través de los derechos. El constitucionalismo garantista como modelo teórico y como proyecto político. Madrid: Trotta, 2014.

FERRAJOLI, Luigi. Direito e razão: teoria do garantismo penal. Tradutores Ana Paula Zomer Sica, Fauzi Hassan Choukr, Juarez Tavares e Luiz Flávio Gomes. $4^{\mathrm{a}}$ ed. São Paulo: Ed. Revista dos Tribunais, 2002.

FERRAJOLI, Luigi. Para um Ministério Público como instituição de garantia. Revista do Ministério Público. 153, janeiro a março de 2018.

GOMES, Marcus Allan. Mídia e sistema penal: as distorções nos meios de comunicação. Rio de Janeiro: Revan, 2015.

GLOECKNER, Ricardo Jacobsen; RAMOS, Marcelo Butelli. Os sentidos do populismo penal: Uma análise para além da condenação ética. DELICTAE: Revista de Estudos Interdisciplinares sobre o Delito, [S.1.], v. 2, n. 3, p. 248, dez. 2017. https://doi.org/10.24861/2526-5180.v2i3.39

HOLMES, Stephen. Precommitment and the paradox of democracy. In Passions and Constraints. Chicago: University of Chicago Press, 1995. P. 134-177.

KRAMER, Larry. The people themselves. Oxford: Oxford University Press, 2004. (Kindle)

MAZZILLI, Hugo N. Manual do Promotor de Justiça. São Paulo: Saraiva, 2a ed., 1991.

MBEMBE, Achille. Necropolitics. Public Culture, Volume 15, Number 1, Winter 2003, pp. 11-40.

MELO, Marcos Eugênio Vieira. Neoinquisitorialismo processual penal e a contaminação do julgador com os atos de investigação: a burla interna no processo penal brasileiro como obstáculo ao contraditório. Revista Brasileira de Direito Processual Penal, Porto Alegre, vol. 6, n. 2, p. 951-992, mai./ago. 2020. https:// doi.org/10.22197/rbdpp.v6i2.314 
MENDES, Soraia R. Editorial dossiê "Colaboração premiada e justiça criminal negocial”: novos e múltiplos olhares. Revista Brasileira de Direito Processual Penal, Porto Alegre, vol. 3, n. 1, p. 31-38, jan./abr. 2017. https://doi.org/10.22197/rbdpp.v3i1.56 MÉNDEZ HINCAPÍE, Gabriel y SANÍN RESTREPO, Ricardo. "La Constitución encriptada. Nuevas formas de emancipación del poder global”. Revista de Derechos Humanos y Estudios Sociales, UASLP-UAA-US, no. 8, pp. 97-120, julio - diciembre 2012. MOURA, Daniela Souza Filho. A investigação criminal direta pelo ministério público em face do sistema acusatório de processo penal. Revista do Ministério Público do Estado do Pará, Belém, v. 7, n. 7, p. 43-66, 2012.

PALUDO, Januário; LIMA, Carlos Fernando dos Santo e ARAS, Vladimir. Forçastarefas: direito comparado e legislação aplicável - MPF. Brasília: Escola Superior do Ministério Público da União, 2011.

PRADO, Geraldo Luiz Mascarenhas. A investigação criminal e a PEC 37. Boletim IBCCRIM, São Paulo, v. 21, n. 248, p. 5-7, jul. 2013.

RIBEIRO, Marcelo H. M.; SAMPAIO, André R.; FERREIRA, Amanda A. A influência dos elementos de informação do inquérito policial na fundamentação da sentença penal condenatória: uma análise das sentenças prolatadas pelas varas criminais de Maceió/AL. Revista Brasileira de Direito Processual Penal, Porto Alegre, vol. 6, n. 1, p. 175-210, jan./abr. 2020. https://doi.org/10.22197/rbdpp.v6i1.299

SANTORO, Antonio E. R. A imbricação entre maxiprocessos e colaboração premiada: o deslocamento do centro informativo para a fase investigatória na Operação Lava Jato. Revista Brasileira de Direito Processual Penal, Porto Alegre, vol. 6, n. 1, p. 81-116, jan./abr. 2020. https://doi.org/10.22197/rbdpp.v6i1.333

SCHMITT, Carl. O Conceito do Político. Tradução de Alvaro L. M. Valls. Petrópolis: Vozes, 1992.

SOUZA, Artur de Brito Gueiros; CONSENTINO, Luís Cláudio Senna. Atuação do Ministério Público nas investigações de corrupção no Brasil. In: COMPLIANCE e temas relevantes de direito e processo penal: estudos em homenagem ao advogado e professor Felipe Caldeira. Organização de Bruno Espiñeira LEMOS et al. Belo Horizonte: D’Plácido, 2018, p. 139-153.

VIEIRA. Oscar Vilhena. A Constituição e sua reserva de justiça. Um ensaio sobre os limites materiais ao poder de reforma. São Paulo: Malheiros, 1999.

VIEIRA, Renato Stanziola. Procedimento investigatório criminal, esse outro desconhecido. Boletim IBCCRIM, São Paulo, v. 14, n. 168, p. 12-13, nov. 2006.

ZANETI, Hermes. CPC/2015: O Ministério Público como Instituição de Garantia e as Normas. Revista Jurídica Corregedoria Nacional: A Atuação Orientadora das Corregedorias do Ministério Público, volume II/ Conselho Nacional do Ministério Público. Brasília: CNMP, 2017. 


\section{Informações adicionais e declarações dos autores (integridade científica)}

Agradecimentos (acknowledgement): O autor Antonio Eduardo Ramires Santoro agradece à FAPERJ - Fundação Carlos Chagas Filho de Amparo à Pesquisa do Estado do Rio de Janeiro pelo financiamento que vem sendo feito ao projeto de pesquisa pela bolsa Jovem Cientista do Nosso Estado, que possibilitou a realização deste trabalho. Os autores agradecem ao professor Luiz Fernando Castilhos Silveira, pelas sugestões e opções de tradução para o inglês dos termos utilizados na presente pesquisa.

Declaração de conflito de interesses (conflict of interest declaration): os autores confirmam que não há conflitos de interesse na realização das pesquisas expostas e na redação deste artigo.

Declaração de autoria e especificação das contribuições (declaration of authorship): todas e somente as pessoas que atendem os requisitos de autoria deste artigo estão listadas como autores; todos os coautores se responsabilizam integralmente por este trabalho em sua totalidade.

- Antonio Eduardo Ramires Santoro: projeto e esboço inicial (conceptualization), desenvolvimento da metodologia (methodology), revisão bibliográfica (investigation), redação (writing - original draft), participação ativa nas discussões dos resultados (validation), revisão crítica com contribuições substanciais (writing - review and editing), aprovação da versão final.

- Carolina Cyrillo: projeto e esboço inicial (conceptualization), desenvolvimento da metodologia (methodology), levantamento bibliográfico (investigation), revisão bibliográfica (investigation), redação (writing - original draft), participação ativa nas discussões dos resultados (validation), revisão crítica com contribuições substanciais (writing - review and editing), aprovação da versão final.

Declaração de ineditismo e originalidade (declaration of originality): os autores asseguram que o texto aqui publicado não foi divulgado anteriormente em outro meio e que futura republicação somente se realizará com a indicação expressa da referência desta publicação original; também atestam que não há plágio de terceiros ou autoplágio. 


\section{Dados do processo editorial}

(http://www.ibraspp.com.br/revista/index.php/RBDPP/about/editorialPolicies)

- Recebido em: 24/07/2020

- Controle preliminar e verificação de plágio: 27/07/2020

- Avaliação 1: 04/08/2020

- Avaliação 2: 11/08/2020

- Avaliação 3: 11/08/2020

- Avaliação 4: 12/08/2020

- Decisão editorial preliminar: 23/08/2020

- Retorno rodada de correções 1: 13/09/2020

- Decisão editorial preliminar 2: 14/09/2020

- Retorno rodada de correções 2: 14/09/2020

- Decisão editorial final: 15/09/2020
Equipe editorial envolvida

- Editor-chefe: 1 (VGV)

- Editor-associado: 1 (RO)

- Revisores: 4

\section{COMO CITAR ESTE ARTIGO:}

SANTORO, Antonio E. R.; CYRILLO, Carolina. As Forças-Tarefas do Ministério Público Federal: o discurso político punitivo anticorrupção na instituição de garantias. Revista Brasileira de Direito Processual Penal, Porto Alegre, vol. 6, n. 3, p. 1271-1300, set./dez. 2020. https://doi.org/10.22197/rbdpp.v6i3.431

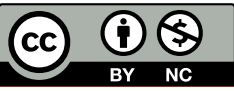

Esta obra está licenciada com uma Licença Creative Commons Atribuição-NãoComercial 4.0 Internacional. 